\title{
Skin physiology and safety of microfocused ultrasound with visualization for improving skin laxity
}

This article was published in the following Dove Press journal:

Clinical, Cosmetic and Investigational Dermatology

\author{
Martina Kerscher' \\ Arti Tania Nurrisyanti' \\ Christine Eiben-Nielson' \\ Susanne Hartmann ${ }^{2}$ \\ Judith Lambert-Baumann² \\ 'University of Hamburg, Division \\ of Cosmetic Sciences, Hamburg, \\ Germany; ${ }^{2}$ Merz Pharmaceuticals, \\ Frankfurt/Main, Germany
}

\begin{abstract}
Purpose: The efficacy of microfocused ultrasound with visualization (MFU-V; Ultherapy ${ }^{\circledR}$ ) has been demonstrated in clinical studies and daily practice. However, data addressing skin physiology after MFU-V treatment are lacking. This observational evaluation was aimed to assess skin physiology before and after MFU-V treatment using noninvasive biophysical measurements.

Patients and methods: Twenty-two female patients with moderate-to-severe skin sagging at the jawline and submental region on the Merz Aesthetics Scale obtained a single MFU-V treatment according to protocol. Skin function measurements focused on short-term effects up to 3 days and long-term effects up to 24 weeks after treatment. Skin temperature, transepidermal water loss, skin hydration, erythema, elasticity, and skin thickness and density were evaluated under standardized conditions. Pain was assessed using a validated numeric visual analog scale. Results: Skin temperature remained in a physiologic range and no significant increase was noted at day 3 after MFU-V treatment. Transepidermal water loss, hydration, and erythema values were fairly stable and showed no significant differences at short- and long-term measurements vs baseline. At week 4 after a single MFU-V treatment, gross and net elasticity values were significantly decreased ( $P=0.003$ and $P=0.0001$, respectively), followed by significantly increased values at week $12(P=0.015, P=0.046)$ and week $24(P=0.001, P=0.049)$. Edema due to MFU-V treatment resolved without sequelae. For all patients, pain diminished shortly after treatment. No adverse events occurred during the 24-week follow-up period.

Conclusions: MFU-V treatment is well tolerated and it does not alter the epidermal barrier function or physiology of skin. Significant increase in the elasticity of skin was observed at 12 and 24 weeks after a single treatment, which reflects improvement in dermal tissue function. These short- and long-term effects are congruous with the mode of action of MFU-V due to a proven intrinsic tissue remodeling process.
\end{abstract}

Keywords: skin lifting, tightening, neocollagenesis, epidermal barrier, elasticity, energy-based device

\section{Introduction}

Patients with skin laxity of the face and neck often seek skin rejuvenation with noninvasive, safe, effective, and rapid cosmetic treatments. Microfocused ultrasound with visualization (MFU-V; Ulthera ${ }^{\circledR}$ System, Merz North America, Raleigh, NC, USA) is characterized by precise delivery of ultrasound energy at predefined depths with simultaneous visualization. ${ }^{1,2}$ This technology enables the induction of precise thermal coagulation points of $65^{\circ} \mathrm{C}$ without damaging skin surface. ${ }^{3}$ It also targets the superficial muscular aponeurotic system (SMAS) to produce focused thermal collagen denaturation and subsequent neocollagenesis. ${ }^{4}$
Correspondence: Martina Kerscher University of Hamburg, Division of Cosmetic Sciences, Martin Luther King Platz 6, D-20146 Hamburg, Germany Tel +4940428387234

Email Martina.Kerscher@uni-hamburg.de 
The MFU-V medical device is approved by the US Food and Drug Administration. According to the CE-mark, MFU-V is indicated for noninvasive lifting and sculpting of the upper face, lower face, neck, and décolleté. ${ }^{5}$ Clinical studies have demonstrated that MFU-V is effective as a noninvasive lifting and sculpting device of the upper face, ${ }^{6}$ lower face, ${ }^{7}$ neck, ${ }^{8,9}$ and décolleté. ${ }^{10}$

Patients expect noninvasive cosmetic treatments, especially those intended for facial rejuvenation, to be effective and safe with minimal recovery time. Reviews from clinical studies and post-marketing use of MFU-V suggest that energy-based devices can fulfill these desired parameters. ${ }^{11,12}$

The primary objective of this evaluation was to assess skin physiology before and both short and long term after MFU-V treatment in patients with moderate to severe skin laxity at jawline and submental region.

\section{Patients and methods Design}

This observational, single-center, open-label safety evaluation was performed using anonymized data received through objective standardized measurements for skin physiology in routine practice. All participants were provided with detailed written and oral information and written informed consent was obtained before any treatments and assessments as suggested by local ethics committee (Ethikkommission der Ärztekammer Hamburg). The evaluation was performed in accordance with the principles of the 1975 Declaration of Helsinki. MFU-V was performed on-label for noninvasive lifting and sculpting of the lower face and submental region.

\section{Microfocused ultrasound with visualization}

MFU-V combines precise delivery of microfocused ultrasound to dermal/subdermal tissues, including the SMAS, with simultaneous visualization of the treatment area. Before delivery of microfocused ultrasound, an appropriate image ensures heat delivery to the intended area. MFU-V is available commercially and consists of a control unit with touch screen, a hand piece, and proprietary transducers (DeepSEE ${ }^{\circledR}$, Ulthera/Merz, Mesa, AZ, USA).

\section{Cohort}

\section{Patients}

Twenty-two healthy women with moderate-to-severe skin laxity have been treated with MFU-V due to their clinical needs and following available treatment guidelines. No contraindication existed in any of the patients (Table 1). Subjects' characteristics were documented before MFU-V treatment was performed. Soft-tissue laxity was assessed clinically using the five-point Merz Aesthetics Scale (MAS) for the lower face. ${ }^{13}$ Objective measurements of skin functions were taken under standardized conditions before, immediately after, and 12 and 24 weeks after MFU-V treatment.

\section{Procedure}

At baseline, ibuprofen ( $800 \mathrm{mg}$ orally, once) was administered at the discretion of the treating physician and participant 1 hour before treatment. A single MFU-V treatment was performed on the lower face, submental region, and neck according to the MFU-V treatment protocol consecutively with two transducers: one at $4.0 \mathrm{MHz}$ (depth of $4.5 \mathrm{~mm}, 350$ lines in total) followed by one at 7.0 $\mathrm{MHz}$ (depth of $3.0 \mathrm{~mm}, 270$ lines in total; Figure 1). Each enrolled subject completed 12-week or 24-week follow-up visits or both.

\section{Biophysical evaluation}

A number of biophysical parameters were measured to assess the skin physiology prior to the MFU-V treatment,

Table I Inclusion and exclusion criteria for MFU-V treatment

\begin{tabular}{|c|c|}
\hline Inclusion & Exclusion \\
\hline Female & Pregnant or lactating \\
\hline Age $30-65$ years & Open wounds or lesions in the treatment area; severe or cystic acne in the treatment area \\
\hline MAS grade $2-3$ for lower face/submental skin & Excessive skin laxity on the lower face and neck \\
\hline laxity (moderate to severe) & \\
\hline $\begin{array}{l}\text { Naïve to minimally invasive or surgical cosmetic } \\
\text { treatment }\end{array}$ & Presence of metallic stent or active implants in the treatment area \\
\hline Willing and able to provide informed consent & Mental illness \\
\hline \multirow[t]{2}{*}{ Willing to attend follow-up visits } & Inability to understand the protocol or to give written consent \\
\hline & $\begin{array}{l}\text { History of minimally invasive aesthetic procedures (eg, dermal fillers, laser therapy, } \\
\text { implants, dermabrasion, and deep facial peel) in the treatment area within the last } 24 \\
\text { months }\end{array}$ \\
\hline
\end{tabular}

Abbreviation: MFU-V, microfocused ultrasound with visualization. 
immediately after treatment, and during each post-treatment follow-up visit at day 3 , week 4 , week 12 , and week 24 (Figure 2). All measurements were obtained under standardized dermatological laboratory condition with an acclimatization period of at least 30 minutes in an airconditioned room at $20^{\circ} \mathrm{C}-21^{\circ} \mathrm{C}$ and relative humidity of $40 \%-50 \%$. Parameters assessed were in vivo transepidermal water loss (TEWL), skin hydration, erythema, viscoelasticity properties, and skin thickness and density. Measurements were taken from the same site on both cheeks using a template.

\section{Transepidermal water loss}

TEWL was assessed using a Tewametry (Tewameter ${ }^{\circledR}$ TM 300; Courage \& Khazaka, Cologne, Germany). In brief, a hollow cylindrical chamber containing two hygro and temperature sensors situated at different levels above the skin surface measures relative humidity. The vapor pressure difference between the two sensor sites determines the TEWL and is given in grams per hour per square meter $(\mathrm{g} /$ hour $\left./ \mathrm{m}^{2}\right) .{ }^{14}$ One continuous measurement of 30 seconds was

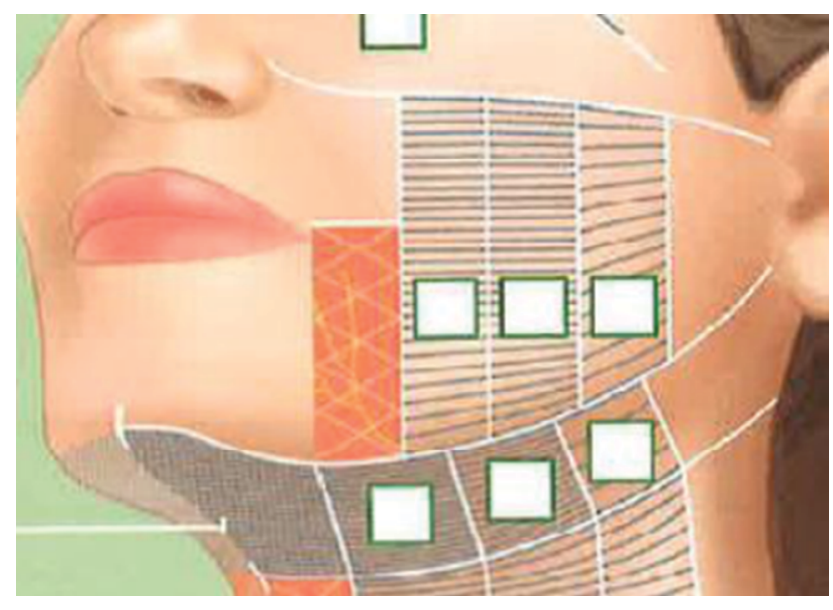

Figure I Treatment scheme for MFU-V treatment of lower face and submental region.

Abbreviation: MFU-V, microfocused ultrasound with visualization. recorded at each visit at predefined localizations within the treated areas. ${ }^{15}$

\section{Stratum corneum hydration}

Stratum corneum hydration was determined using Corneometry (Corneometer ${ }^{\circledR}$ CM 825; Courage \& Khazaka, Cologne, Germany). Briefly, the measurement of the electrical capacity of the stratum corneum directly correlates to hydration. The measured capacity is given in arbitrary units (CM units), ranging from 0 to 120 , specifying very dry skin to $<30 \mathrm{CM}$, dry skin from 30 to $40 \mathrm{CM}$ and normal skin $>40 \mathrm{CM} .{ }^{16}$ Three measurements were taken at each visit at predefined skin locations within the treated areas.

\section{Skin redness (erythema)}

Erythema was measured using mexametry (Mexameter ${ }^{\circledR} \mathrm{MX}$ 18; Courage \& Khazaka, Cologne, Germany). The Mexameter consists of 16 circularly arranged light-emitting diodes that emit green, red, and near-infrared light at three specific light wavelengths of 568, 660, and $880 \mathrm{~nm}$. The Erythema index is computed based on the intensity of the absorbed and reflected green and red light for hemoglobin at wavelengths of 568 and $880 \mathrm{~nm}$, respectively.

\section{Skin elasticity}

Elasticity of the skin was assessed using cutometry (Cutometer ${ }^{\circledR}$ MPA 580; Courage \& Khazaka, Cologne, Germany). A defined vacuum ( -450 mbar) was applied to the respective skin surface area and turned off to let the skin recover. A probe with $2 \mathrm{~mm}$ diameters was used. The skin properties were calculated from measurement of vertical deformation of the skin as well as timing using the software of the instrument. The parameters of interest were gross (R2) and net elasticity (R5).

\section{Skin thickness and density}

Both parameters were determined using an ultrasound scanner with a frequency of $20 \mathrm{MHz}\left(\mathrm{DUB}^{\circledR} 20\right.$; Taberna Pro

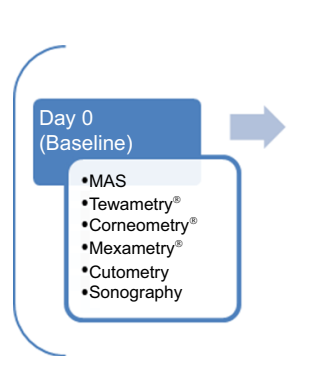

Short-term effect

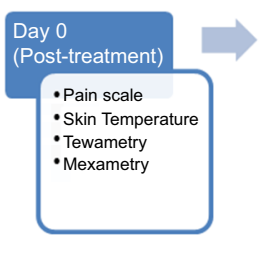

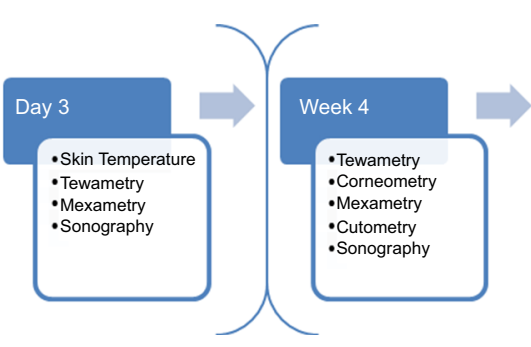

Long-term effect

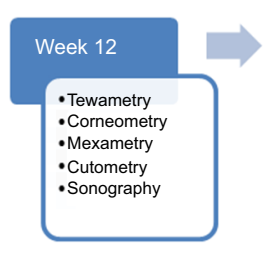

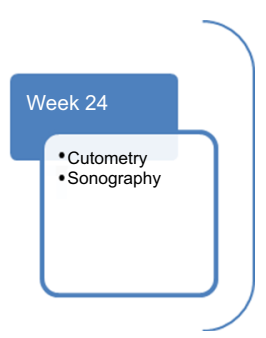

Figure 2 Overview of visits and biophysical measurement of dermal function. 
Medicum, Lueneburg, Germany). Sonographic assessment of skin thickness was based on the intensity of reflected ultrasound waves in the respective skin area. Skin thickness was calculated based on values from amplitudes of reflected waves and depths of the skin. The B-Scan mode was used to determine skin density.

\section{Skin temperature}

Skin temperature was measured before, 30 minutes and 3 days after the treatment using a thermistor (113050, Rochester, Inc. Rochester, NY, USA). Temperature is measured by placing the half inch diameter surface probe of the thermistor on the skin until equilibrium is reached (defined by a $<0.2^{\circ} \mathrm{C}$ change in temperature of $>15$ seconds).

\section{Safety}

Tolerability and safety assessments were performed immediately after the MFU-V treatment and on follow-up visits. Patients' subjective pain assessment using a visual analog scale (VAS; 11 points: $0=$ no pain, $10=$ worst pain imaginable) was performed immediately after treatment. At each follow-up visit, all patients were examined for edema and adverse events.

\section{Statistical analysis}

Statistical analyses were carried out with $\mathrm{SPSS}^{\circledR}$ v 22.0 (IBM, Armonk, NY, USA). Kolmogorov-Smirnov test was used to assess normal distribution of the data. A parametric $t$-test for paired samples was applied on normally distributed data, and the nonparametric Wilcoxon signed-rank test was used when the data did not appear normally distributed. $P$-values of $\leq 0.05$ were considered as statistically significant, $P$-values of $\leq 0.01$ were considered as highly significant and very highly significant when the $P$-value was $P \leq 0.0001$.

\section{Results}

\section{Demographics}

Twenty-two Caucasian women (mean age, 52.32 \pm 9.32 years; Fitzpatrick skin type, I-III; body mass index, 20-30 $\mathrm{kg} / \mathrm{m}^{2}$ ) with moderate-to-severe skin laxity (mean MAS score, $2.8 \pm 0.87$ ) were treated with MFU-V and eligible for evaluation.

\section{Safety}

No adverse events occurred during the course of the evaluation, and no patients withdrew from the evaluation due to an adverse event. Dermal edema in the treatment area was observed 3 days after MFU-V but resolved completely by week 4. Sonography illustrated a representative example of the course of edema (Figure 3).

Self-assessment of pain during MFU-V treatment of the lower face and submental region revealed minimalto-moderate pain (VAS score, 1-5) for 15 cases, with 7 patients reporting minimal pain and 6 patients reporting moderate pain. For all patients, pain diminished shortly after treatment.
A

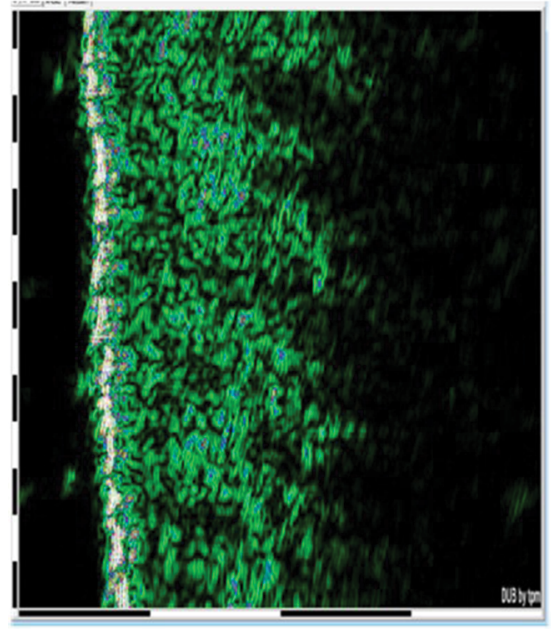

Baseline
B

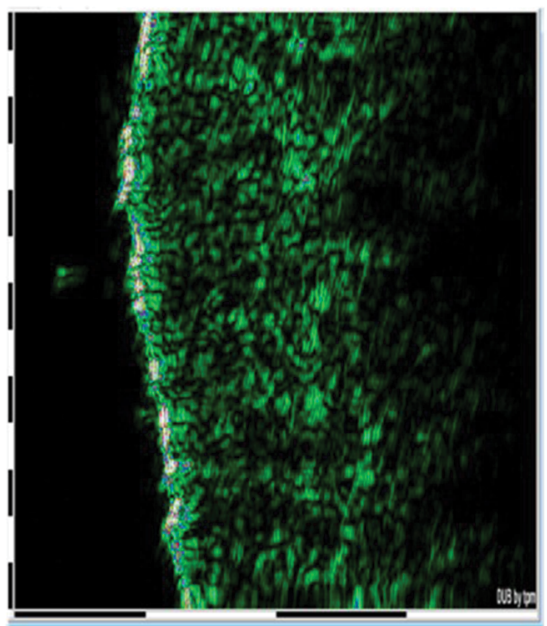

72 hours after MFU-V treatment
C

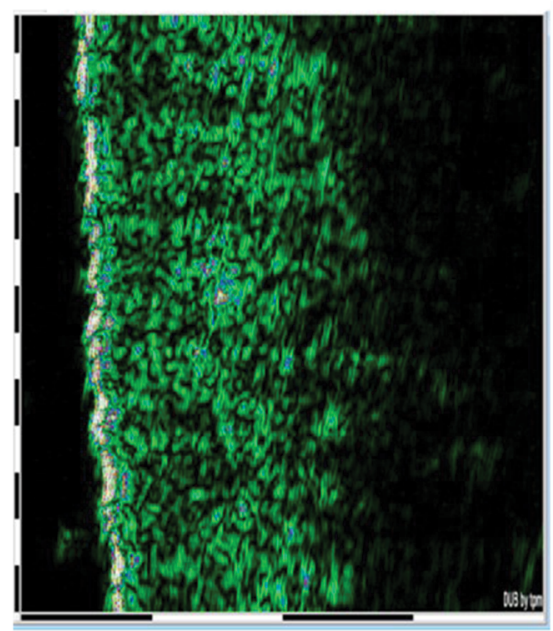

4 weeks after MFU-V treatment

Figure 3 Course of edema: (A) before MFU-V, (B) edema at 72 hours after MFU-V, and (C) resolution of edema. Abbreviation: MFU-V, microfocused ultrasound with visualization. 


\section{Skin temperature}

Mean skin temperature was significantly increased immediately after treatment $(P<0.05)$ from $31.536^{\circ} \mathrm{C} \pm 1.369^{\circ} \mathrm{C}$ at baseline to $32.323^{\circ} \mathrm{C} \pm 1.315^{\circ} \mathrm{C}$. Measurements at day 3 after MFU-V treatment showed decreased mean values of $31.468^{\circ} \mathrm{C} \pm 1.08^{\circ} \mathrm{C}$ (Figure 4 ).

\section{Transepidermal water loss}

Evaporimetry demonstrated physiologic values before, immediately after, and 3 days after treatment (Figure 5), as well as at 4 and 12 weeks after MFU-V treatment for longterm assessment (Figure 6). At baseline, mean values were $4.555 \pm 1.651 \mathrm{~g} /$ hour $/ \mathrm{m}^{2}$. They were increased slightly immediately after MFU-V to $5.295 \pm 2.145 \mathrm{~g} / \mathrm{hour} / \mathrm{m}^{2}$ and declined to $4.755 \pm 2.175 \mathrm{~g} / \mathrm{hour} / \mathrm{m}^{2}$ (day 3 ), $3.685 \pm 1.525 \mathrm{~g} / \mathrm{hour} / \mathrm{m}^{2}$
(4 weeks) and $4.702 \pm 1.517 \mathrm{~g} /$ hour $/ \mathrm{m}^{2}$ (12 weeks). There were no statistically significant increases for TEWL after MFU-V treatment for either short- or long-term follow-up.

\section{Hydration}

Skin hydration (shown in Corneometer Units) showed a significant decrease over 12 weeks, but values remained fairly stable within the physiologic range before $(54.31 \pm 12.69)$,

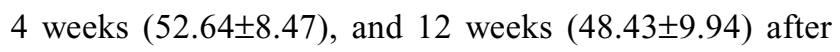
MFU-V treatment (Figure 7).

\section{Erythema}

The mean erythema level (shown in Mexameter Units) at baseline was $313.70 \pm 76.11$, and was increased slightly immediately after treatment to $326.45 \pm 72.84$ and decreased at day

Skin temperature

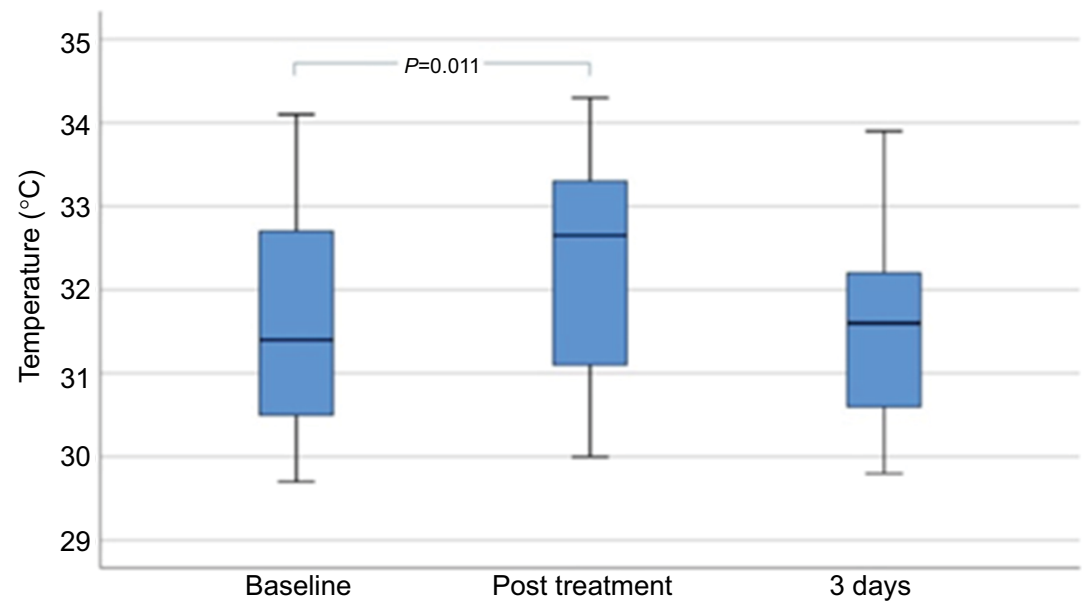

Figure 4 Skin temperature before, immediately, and 3 days after MFU-V treatment.

Abbreviation: MFU-V, microfocused ultrasound with visualization.

Short-term measurement of transepidermal water loss

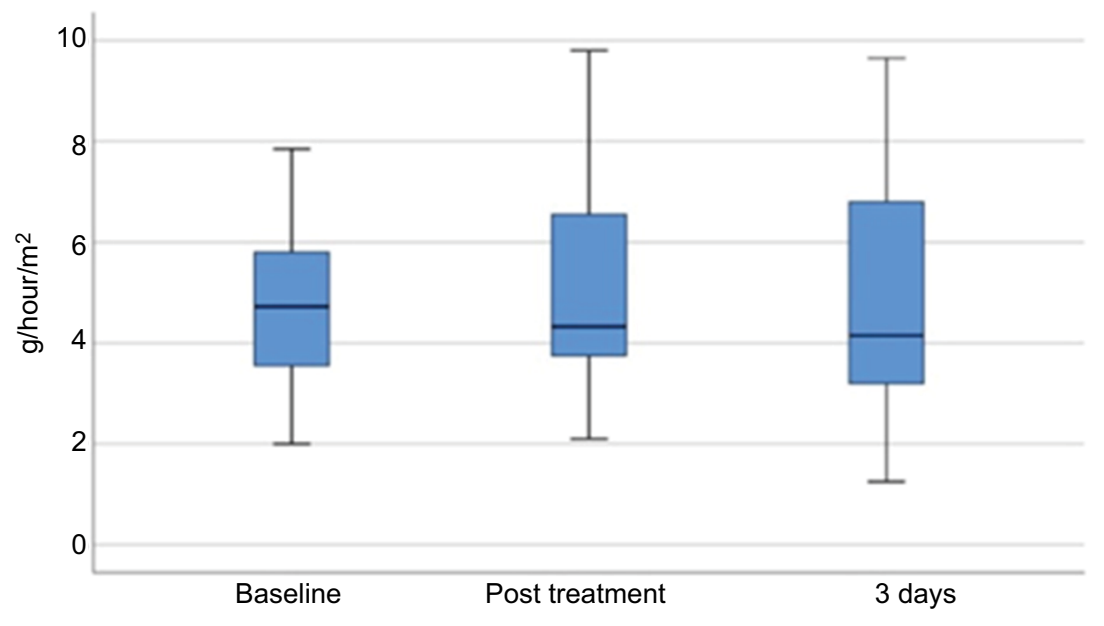

Figure 5 Transepidermal water loss short term after MFU-V treatment.

Abbreviation: MFU-V, microfocused ultrasound with visualization. 
Long-term measurement of transepidermal water loss

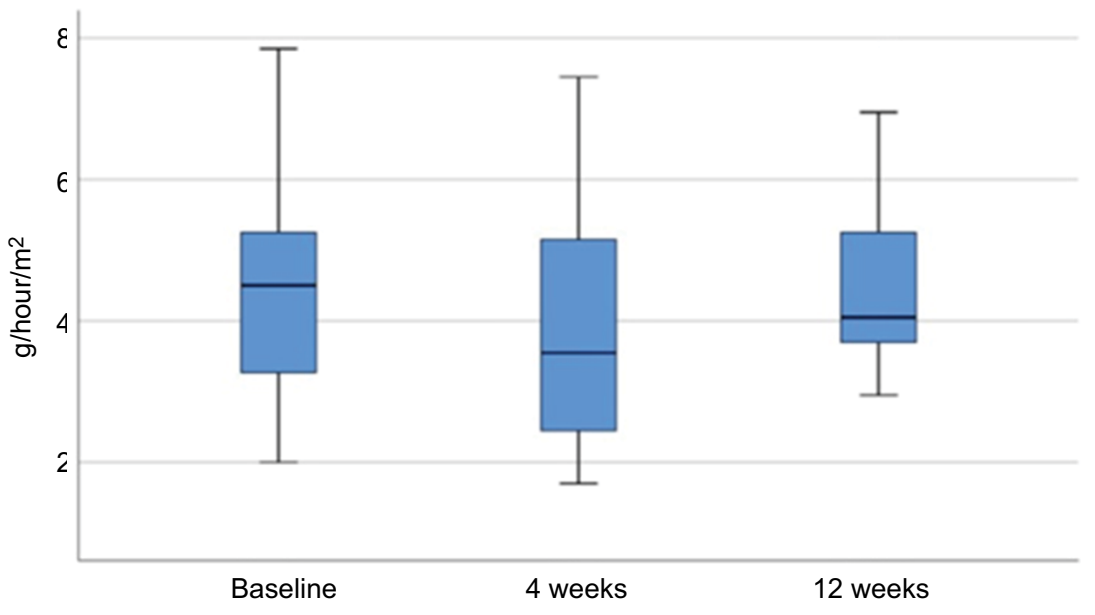

Figure 6 Transepidermal water loss long term after MFU-V treatment.

Abbreviation: MFU-V, microfocused ultrasound with visualization.

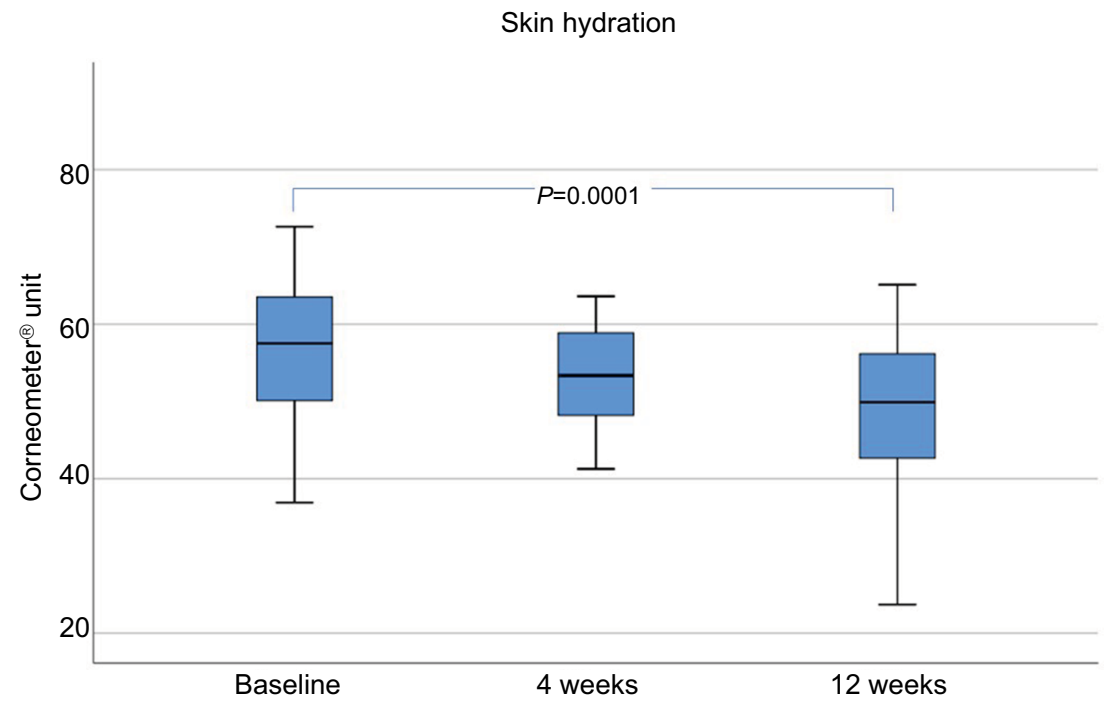

Figure 7 Skin hydration up to 12 weeks after a single MFU-V treatment.

Abbreviation: MFU-V, microfocused ultrasound with visualization.

3 after treatment to $321.36 \pm 70.19$ (Figure 8). Erythema values were further decreased at week 4 (293.63 $\pm 69.51 \mathrm{MU})$ and at week 12 (290.31 $\pm 62.34 \mathrm{MU}$; Figure 9). Erythema values did not demonstrate significant changes compared to baseline for short-term or long-term evaluation.

\section{Elasticity}

A single MFU-V treatment targeting two preselected depths of 4.5 and $3.0 \mathrm{~mm}$ led to a significant increase in net skin elasticity at 12 and 24 weeks, respectively, compared with that at baseline $(P<0.05)$. After 4 weeks, the net elasticity was significantly lower than that at baseline, suggesting physiologic restructuring of collagen tissue. Skin gross elasticity also showed decreased values at week 4 , but significantly increased values at weeks 12 and 24 (Figure 10).

\section{Discussion}

The effectiveness of MFU-V treatment has been demonstrated in several clinical studies ${ }^{6-10}$ and its safety profile has been assessed. ${ }^{12}$ However, prior to this evaluation, no structured data addressed the influence of MFU-V treatment on epidermal/dermal physiologic and biomechanical parameters.

Furthermore, maintenance of skin integrity after treatments for the lifting and tightening of skin is challenging, because damage to the superficial skin layers is unwanted, whereas neocollagenesis in deeper layers is desired. This 
Short-term effect on skin redness (Erythema)

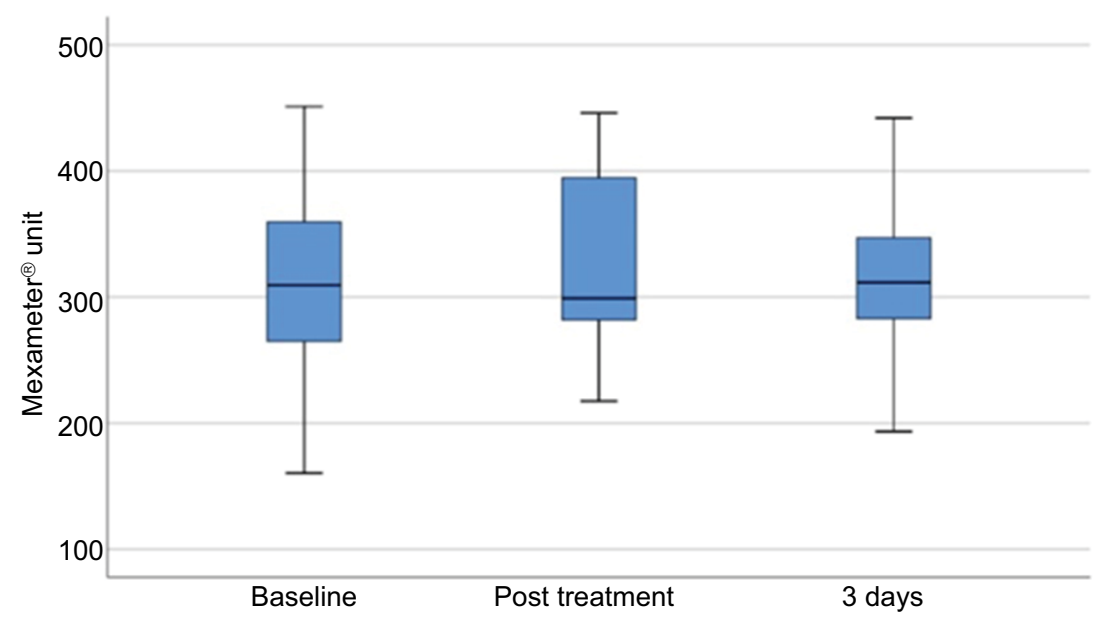

Figure 8 Short-term assessment of erythema.

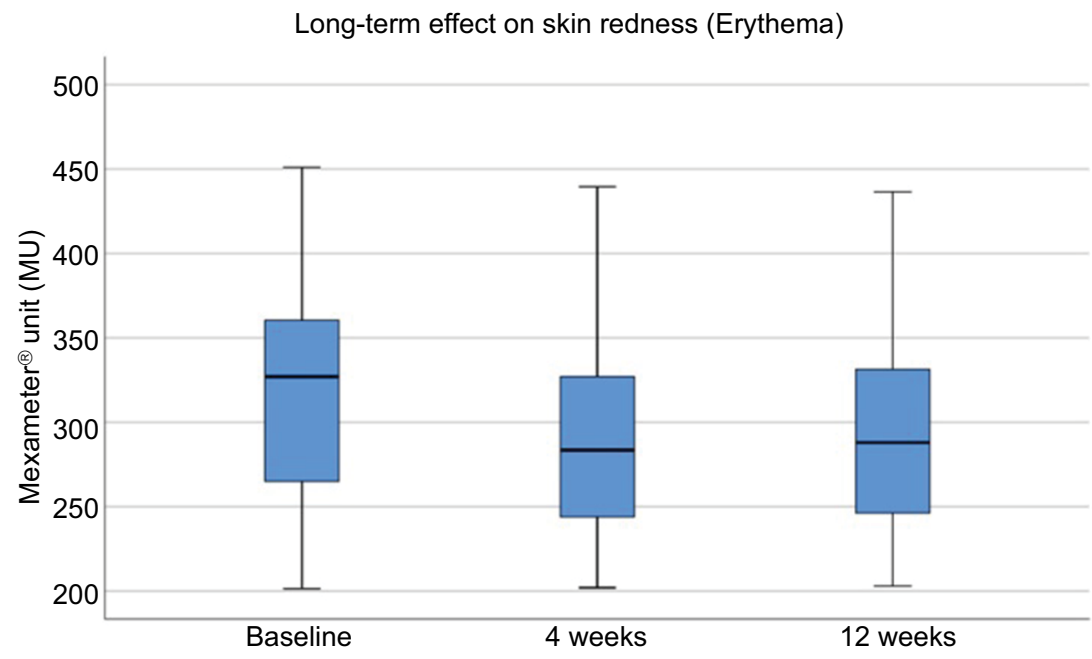

Figure 9 Long-term assessment of erythema.

clinical assessment focused on evaluating short- and longterm physiologic effects of a single MFU-V treatment on skin of the lower face and submental region.

In the present evaluation we provided, for the first time, data for biophysical skin assessments scheduled around MFU-V treatment. We found that after MFU-V treatment, the essential protective skin functions remained in the physiologic range and parameters representing skin tightening were improved. Skin temperature increased within a physiologic range immediately after MFU-V treatment, but there was no significant increase at day 3 after treatment. This observation suggests that MFU-V treatment results in heat being introduced precisely at small thermal coagulation points at intended predefined depths of 4.5 and $3.0 \mathrm{~mm}$.
The epidermal barrier was not disturbed after MFU-V treatment as TEWL, skin temperature, skin hydration, and erythema values did not change significantly either within 3 days of MFU-V treatment or within a long-term follow-up at 24 weeks. These results suggest that this MFU-V technology delivers microfocused ultrasound in a transcutaneous manner without damaging the skin surface.

Net and gross elasticity, as measured by the firmness and involution of the skin, were significantly improved at weeks 12 and 24 . These findings are consistent with clinical studies demonstrating that MFU-V skin-tightening effects most often occur 6 months post treatment, which coincides with neocollagenesis and collagen conversion. ${ }^{17}$ These data also demonstrate that MFU-V can be 
A

Net elasticity
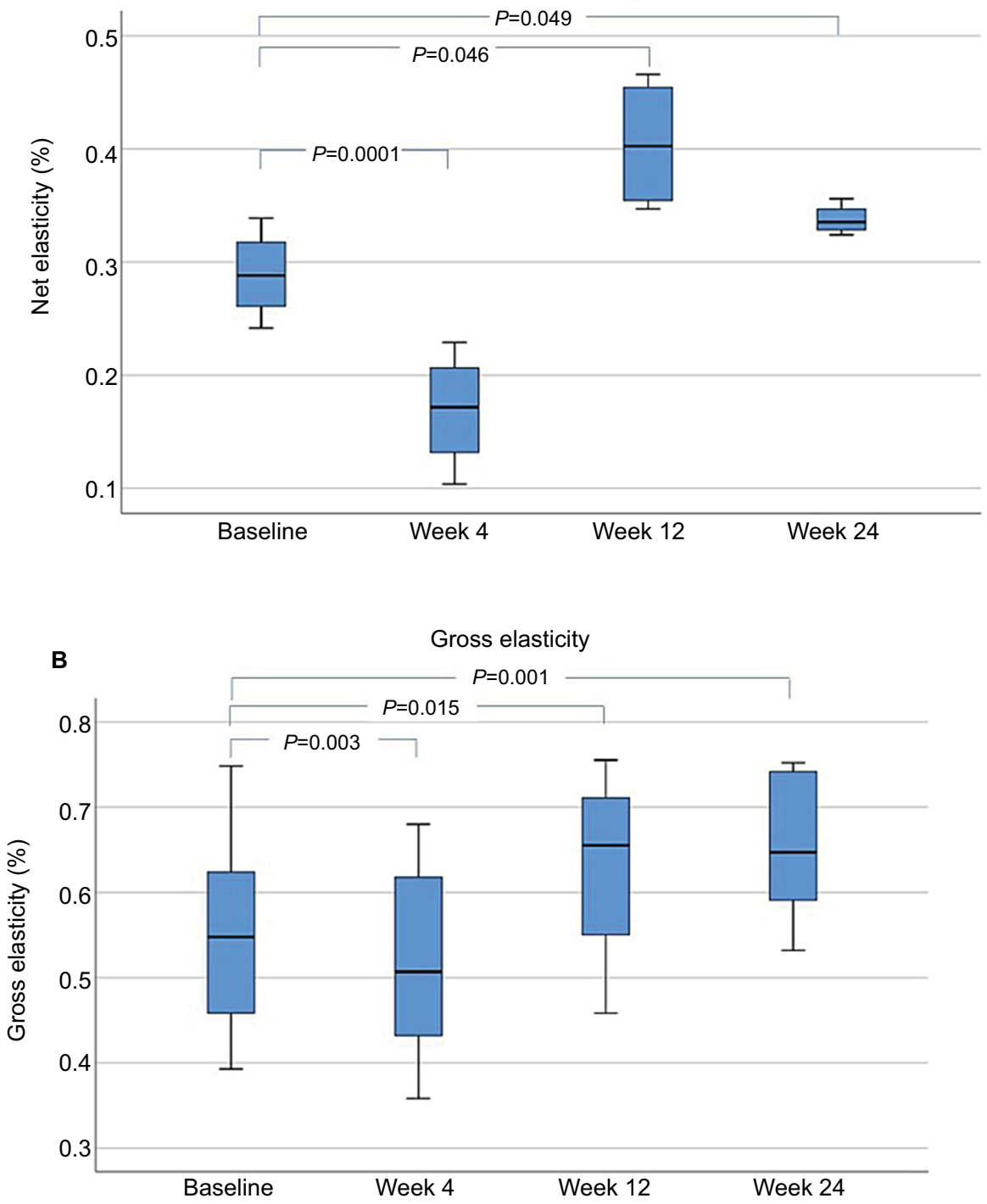

Figure 10 Changes in skin elasticity at the upper face: baseline compared to 4, I2, and 24 weeks after a single MFU-V treatment: (A) net skin elasticity and (B) gross skin elasticity.

Abbreviation: MFU-V, microfocused ultrasound with visualization.

a promising and suitable treatment not only for patients with slight loss of elasticity and skin contour of the face, but also for patients with moderate to severe loss of facial skin elasticity.

Dermal edema was assessed as a parameter of safety in MFU-V treatment. The course of edema resolution might be used as an indicator for wound healing in subsequent combined minimal invasive or surgical cosmetic treatments. The data of this structured assessment suggest that dermal edema might be present 3 days after treatment, but diminished completely by 4 weeks after treatment. Based on these results, waiting for at least 4 weeks before performing any subsequent skin tightening treatments may be prudent. According to consensus recommendations for combined aesthetic treatments, MFU-V might be an effective and safe initial treatment in a combined aesthetic plan. ${ }^{18}$

\section{Conclusion}

MFU-V treatment of the lower face and submental region did not alter skin barrier and skin physiology. However, for the first time, we have demonstrated significant improvement of viscoelastic properties of the skin 12 and 24 weeks post treatment, thereby likely reflecting physiologic dermatologic basis for lifting and tightening of treated areas. 


\section{Author contributions}

MK conducted the evaluation performing visits and instrumental evaluations. ATN and CEN participated in data analyses. $\mathrm{SH}$, JLB, and MK participated in writing, critically revising review, and approving the manuscript. All authors contributed toward data analysis, drafting and revising the paper, gave approval of the final version to be published and agree to be accountable for all aspects of the work.

\section{Disclosure}

MK has received research support and has conducted clinical trials for Merz Pharmaceuticals $\mathrm{GmbH}$ and has acted as a speaker and/or investigator for Merz, Kythera, Q-Med/Galderma, and Pierre Fabre. SH and JLB are employees of Merz Pharmaceuticals. ATN and CEN are scientific employees at the University of Hamburg. The authors report no other conflicts of interest in this work.

\section{References}

1. Laubach HJ, Makin IR, Barthe PG, Slayton MH, Manstein D. Intense focused ultrasound: evaluation of a new treatment modality for precise microcoagulation within the skin. Dermatol Surg. 2008;34(5):727-734.

2. Minkis K, Alam M. Ultrasound skin tightening. Dermatol Clin. 2014;32(1):71-77.

3. White WM, Makin IR, Slayton MH, Barthe PG, Gliklich R. Selective transcutaneous delivery of energy to porcine soft tissues using Intense Ultrasound (IUS). Lasers Surg Med. 2008;40(2):67-75.

4. White WM, Makin IR, Barthe PG, Slayton MH, Gliklich RE. Selective creation of thermal injury zones in the superficial musculoaponeurotic system using intense ultrasound therapy: a new target for noninvasive facial rejuvenation. Arch Facial Plast Surg. 2007;9(1):22-29.

5. Ulthera ${ }^{\circledR}$ System [Instruction for use]. Merz North America, Raleigh, NC; 2018.

6. Chan NP, Shek SY, Yu CS, Ho SG, Yeung CK, Chan HH. Safety study of transcutaneous focused ultrasound for non-invasive skin tightening in Asians. Lasers Surg Med. 2011;43(5):366-375.
7. Oni G, Hoxworth R, Teotia S, Brown S, Kenkel JM. Evaluation of a microfocused ultrasound system for improving skin laxity and tightening in the lower face. Aesthet Surg J. 2014;34(7):1099-1110.

8. Alam M, White LE, Martin N, Witherspoon J, Yoo S, West DP. Ultrasound tightening of facial and neck skin: a rater-blinded prospective cohort study. J Am Acad Dermatol. 2010;62(2):262-269.

9. Werschler WP, Werschler PS. Long-term efficacy of micro-focused ultrasound with visualization for lifting and tightening lax facial and neck skin using a customized vectoring treatment method. JClin Aesthet Dermatol. 2016;9(2):27-33.

10. Fabi SG, Goldman MP, Dayan SH, Gold MH, Kilmer SL, Hornfeldt CS. A prospective multicenter pilot study of the safety and efficacy of microfocused ultrasound with visualization for improving lines and wrinkles of the décolleté. Dermatol Surg. 2015;41(3):327-335.

11. Day D. Microfocused ultrasound for facial rejuvenation: current perspectives. Res Rep Focus Ultrasound. 2014;2:13-17.

12. Hitchcock TM, Dobke MK. Review of the safety profile for microfocused ultrasound with visualization. J Cosmet Dermatol. 2014;13(4): 329-335.

13. Narins RS, Carruthers J, Flynn TC, et al. Validated assessment scales for the lower face. Dermatol Surg. 2012;38(2 Spec No.):333-342.

14. Humbert P, Fanian F, Maibach HI, Agache A. Agache's Measuring the Skin. 2nd ed. New York: Springer; 2017.

15. du Plessis J, Stefaniak A, Eloff F, et al. International guidelines for the in vivo assessment of skin properties in non-clinical settings: Part 2. transepidermal water loss and skin hydration. Skin Res Technol. 2013;19(3):265-278.

16. Heinrich U, Koop U, Leneveu-Duchemin MC, et al. Multicentre comparison of skin hydration in terms of physical-, physiological- and product-dependent parameters by the capacitive method (Corneometer CM 825). Int J Cosmet Sci. 2003;25(1-2):45-53.

17. Fabi SG, Goldman MP. Retrospective evaluation of micro-focused ultrasound for lifting and tightening the face and neck. Dermatol Surg. 2014;40(5):569-575.

18. Carruthers J, Burgess C, Day D, et al. Consensus recommendations for combined aesthetic interventions in the face using botulinum toxin, fillers, and energy-based devices. Dermatol Surg. 2016;42(5): 586-597.
Clinical, Cosmetic and Investigational Dermatology

\section{Publish your work in this journal}

Clinical, Cosmetic and Investigational Dermatology is an international, peer-reviewed, open access, online journal that focuses on the latest clinical and experimental research in all aspects of skin disease and cosmetic interventions. This journal is included on PubMed. The manuscript management system is completely online

\section{Dovepress}

and includes a very quick and fair peer-review system, which is all easy to use. Visit http://www.dovepress.com/testimonials.php to read real quotes from published authors 